\title{
Study of Rare Gases Behavior in Uranium Dioxide
}

\author{
Gaëlle CARLOT ${ }^{1}$, Catherine SABATHIER ${ }^{1}$, Serge MAILLARD ${ }^{1}$, Amélie MICHEL ${ }^{1}$, \\ Guillaume MARTIN ${ }^{1}$, Eric GILABERT' ${ }^{2}$, Franck FORTUNA ${ }^{3}$, Philippe GARCIA ${ }^{4}$ \\ ${ }^{1}$ CEA-DEN-DEC, Service d'Etudes et de Simulation du Comportement des Combustibles, SESC (Cadarache, France) \\ ${ }^{2}$ Centre d'Etudes Nucléaires de Bordeaux Gradignan, CNRS/IN2P3 (Gradignan, France) \\ ${ }^{3}$ Centre de Sciences Nucléaires et de Sciences de la Matière, CNRS/IN2P3 (Orsay, France) \\ ${ }^{4}$ CEA-DEN-DEC, Service Fabrication, Elaboration et Reconditionnement des Combustibles, SFER (Cadarache, France)
}

The behaviour of fission products in uranium dioxide has been a focus of considerable experimental and theoretical attention in the nuclear industry. Xenon and krypton have attracted particular attention due to their high fission yields. During in-reactor irradiation of the nuclear fuel, rare gases are subject to several phenomena: diffusion and precipitation. These phenomena can have adverse consequences on the fuel physical and chemical properties and its in-reactor behavior. When released from the material they induce an increase in the fuel rod pressure detrimental to its integrity. A greater understanding of the mechanisms that underpin rare gas diffusion and precipitation should enable the development of models with a greater predictive capability and also make it possible to optimize fuel microstructures so as to increase the fuel element discharge burnup. The development of models for describing oxide behavior is hindered by the lack of experimental data available. The aim is to contribute to the understanding of the prevailing phenomena and generate sets of fundamental data necessary for modelling rare gas behaviour. The purpose of this work is to better understand the behavior of fission gases by identifying diffusion and bubble nucleation. To do this, studies involving separate effects have been established coupling ion irradiations/implantations with fine characterizations (Thermal Desorption Spectrometry and Transmission electron microscopy).

In order to analyse the mechanisms involved in rare gases diffusion, we carried out Thermal Desorption Spectrometry (TDS) measurements on the PIAGARA (Plateforme Interdisciplinaire pour l'Analyse des GAz Rares en Aquitaine) platform at CENBG laboratory in Bordeaux on $\mathrm{UO}_{2}$ samples implanted at low fluence [Fig. 1]. The experiment involves heating a sample in a small furnace to induce rare gases movement and release and using mass spectrometry to monitor the amount of rare gases released as a function of time. Interpretation of the release experiments has enabled us to determine xenon and krypton diffusion coefficients in uranium dioxide

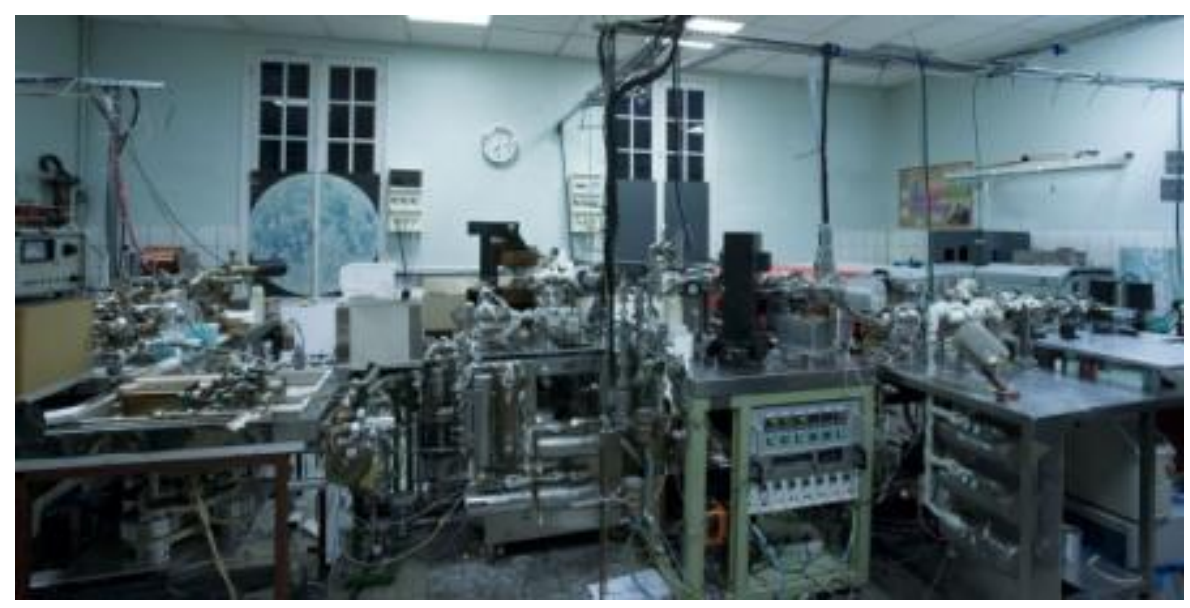

Fig. 1: Plateform PIAGARA at CENBG laboratory

This is an Open Access article distributed under the terms of the Creative Commons Attribution License 4.0, which permits unrestricted use, distribution, and reproduction in any medium, provided the original work is properly cited. 
Transmission electron microscopy (TEM) observations of $\mathrm{UO}_{2}$ polycrystals irradiated in situ with 4 $\mathrm{MeV} \mathrm{Au}$ ions were performed at room temperature (RT) to better understand the mechanisms of cavity and ultimately fission products nucleation in $\mathrm{UO}_{2}$. Experiments were carried out at the JANNuS Orsay facility that enables in situ ion irradiations inside the microscope to be carried out. The majority of $4 \mathrm{MeV}$ gold ions were transmitted through the thin foil, and the induced radiation defects were investigated by TEM. Observations showed that nano-void formation occurs at ambient temperature in $\mathrm{UO}_{2}$ thin foils irradiated with energetic heavy ions under an essentially nuclear energy loss regime. The diameter and density of nano-objects were measured as a function of the gold irradiation dose at RT [Fig. 2]. A previous study [1] has also revealed a similar nano-object population after a $\mathrm{Xe}$ implantation performed at $390 \mathrm{keV}$ at $870 \mathrm{~K}$. The nano-object density was modelled using simple concepts derived from Classical Molecular Dynamics simulations. The results are in good agreement, which suggests a mechanism of heterogeneous nucleation induced by energetic cascade overlaps. This indicates that nano-void formation mechanism is controlled by radiation damage. Such nanovoids are likely to act as sinks for mobile fission products during reactor operation.

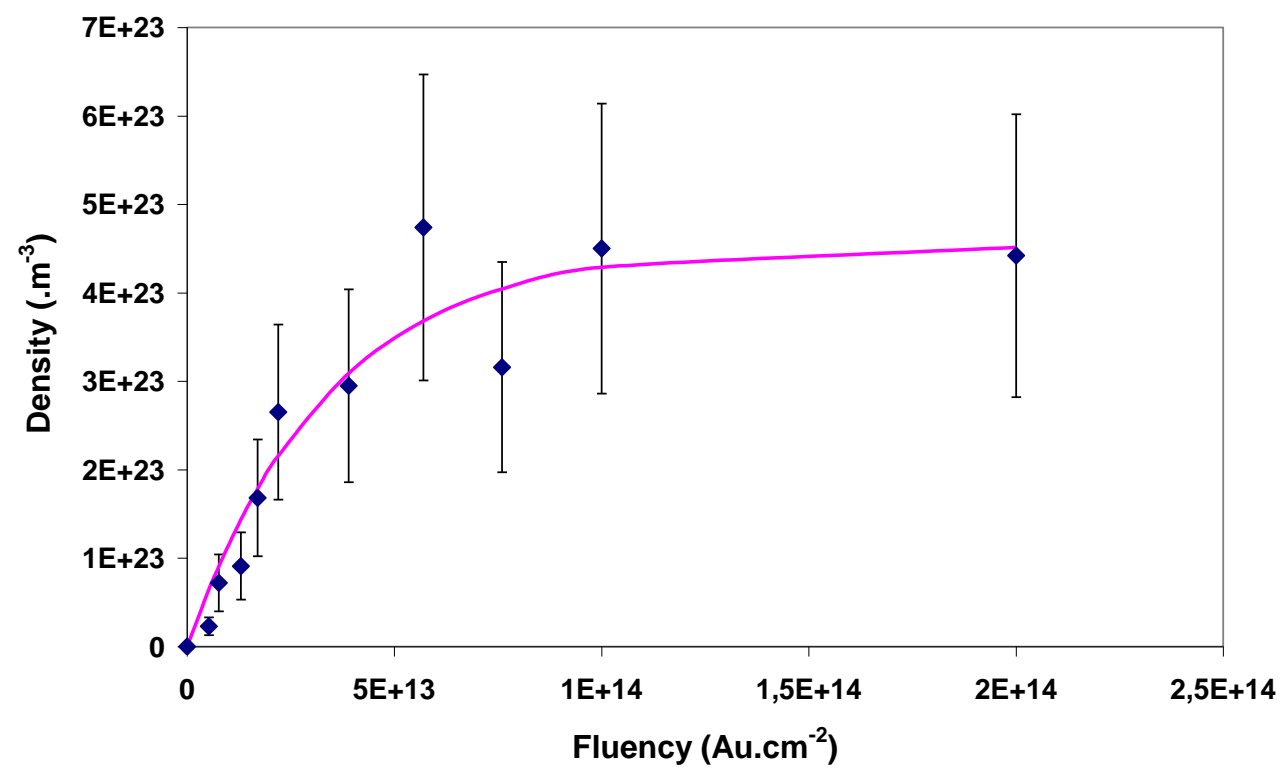

Fig. 2: Nano-void density evolution with Au irradiation at RT from TEM observation.

\section{References}

[1] A. Michel, C. Sabathier, G. Carlot, O. Kaïtasov, S. Bouffard, P. Garcia, C. Valot, Nuclear Instruments and Methods in Physics Research Section B: Beam Interactions with Materials and Atoms, 272 (2012) 218. 


\section{Study of Rare Gas Behaviour in Uranium Dioxide}

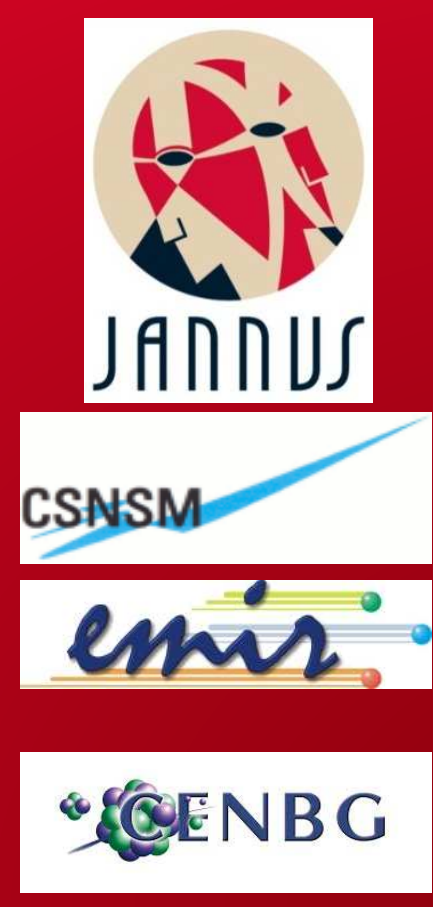

Gaëlle CARLOT, Catherine SABATHIER, Serge MAILLARD, Amélie MICHEL, Guillaume MARTIN, Philippe GARCIA CEA-DEN-DEC

\section{Eric GILABERT}

Centre d'Etudes Nucléaires de Bordeaux Gradignan, CNRS/IN2P3 (Gradignan, France)

Franck FORTUNA

Centre de Sciences Nucléaires et de Sciences de la Matière, CNRS/IN2P3 (Orsay, France) 


\section{Cea CONTEXT : INDUSTRIAL SETTINGS}

MINDS

$\square$ Pressurised Water Reactors (PWR)

$\checkmark 80 \%$ of French electricity production

$\checkmark$ Nuclear Fuel in PWRs

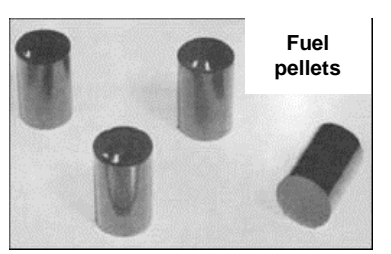

- $\mathrm{UO}_{2}$ pellets inside a tubular zirconium cladding

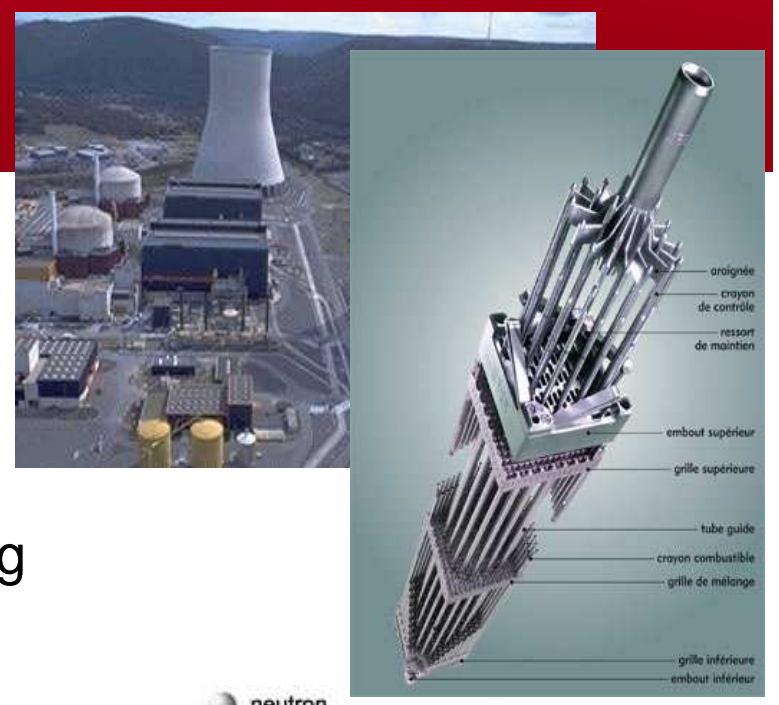

Generation of fission products (FP)

$\checkmark \mathbf{7 0} \%$ solid (Ru, Mo, Zr, Nd...)

$\checkmark \quad 30 \%$ gaseous $(\mathrm{Xe}, \mathrm{Kr})$ or volatile $(\mathrm{Cs}, \mathrm{I})$

$\rightarrow$ At $60 \mathrm{GWd} / \mathrm{tM}$ (5 annual cycles) : $0.5 \%$ at. $\mathrm{Xe}+\mathrm{Kr}$

- Issue

$\checkmark$ Fission Gas Releases (FGR) limit the fuel life time

$\checkmark$ Fuel operating conditions are adjusted to maintain the FGR below a critical limit to keep the cladding integrity 


\section{Cea STUDY GOALS AND EXPERIMENTAL PROCEDURE}

\section{MINDS}

To precisely model the fuel behaviour in-pile conditions Necessity to understand the fuel physico-chemical properties

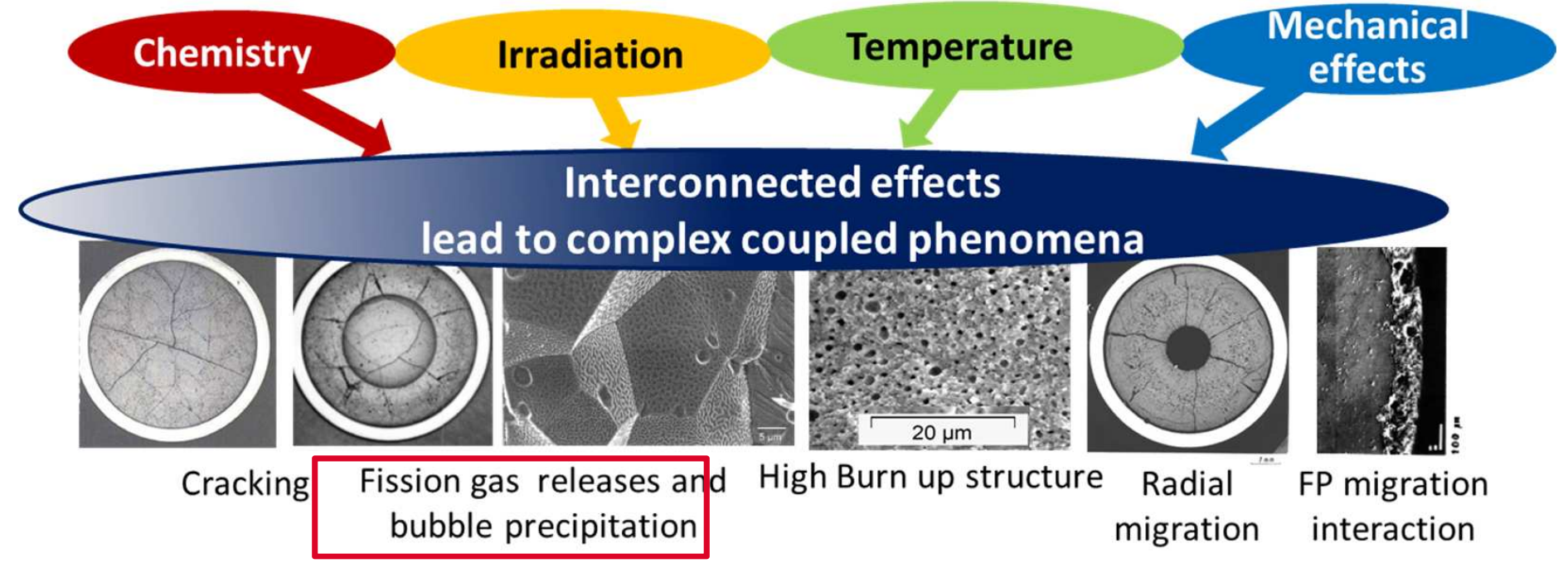

Experimental approach: Separate-effects studies Non-active $\mathrm{UO}_{2}$ - irradiation/implantation $\longrightarrow$ Fine characterisation

Nucleation mechanisms JARกUS ission Electron Microscopy (TEM) JANNUS Orsay Platform

\section{Xenon Diffusion} Thermal Desorption Spectrometry (TDS) PIAGARA Platform 


\section{cea}

\section{IN SITU STUDY OF NUCLEATION JANNUS ORSAY PLATFORM}

MINDS

JANNuS platform in Orsay (France)

Transmission Electronic Microscope coupled with

a 2 MVolt accelerator (ARAMIS) and a 190 kVolt implanter (IRMA)

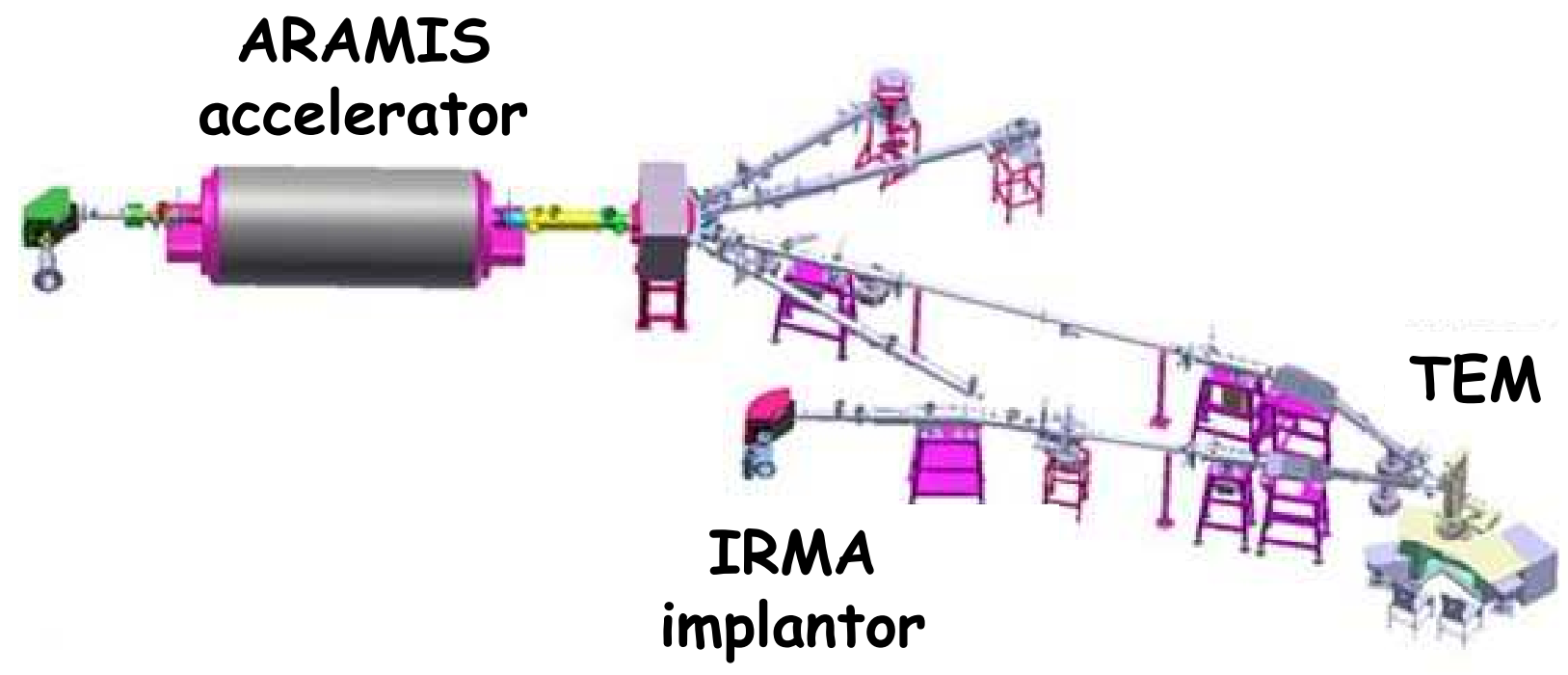

\section{FEI Tecnai G2} 200 kVolt

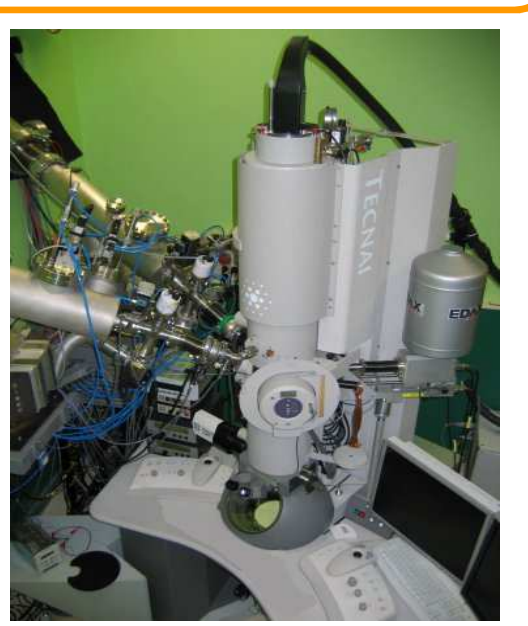




\section{CQZ IN SITU STUDY OF XE BUBBLE NUCLEATION IRMA IMPLANTATIONS AND TEM}

MIN口S

In situ study of Xe bubble nucleation coupling IRMA implantations and TEM

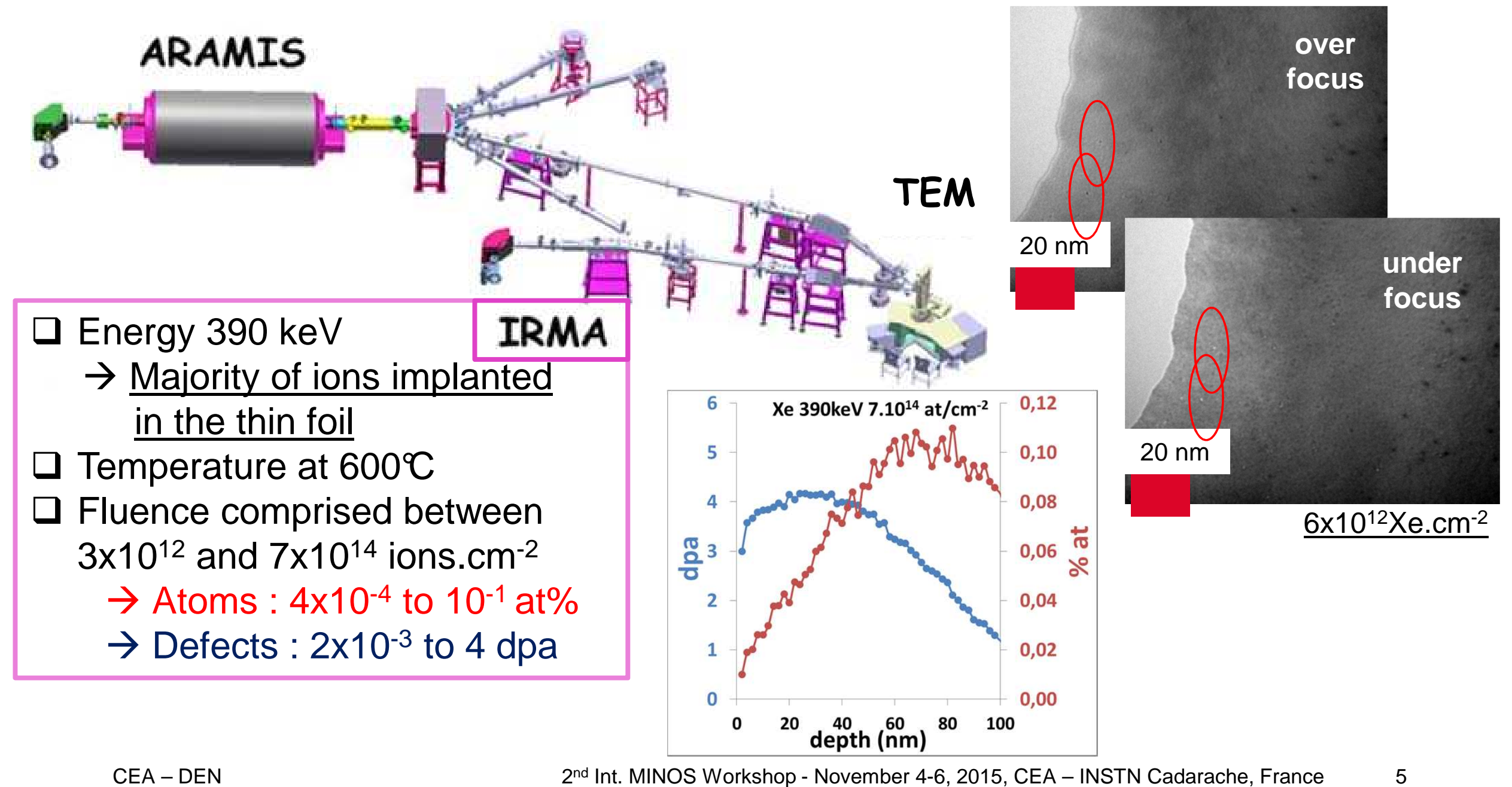




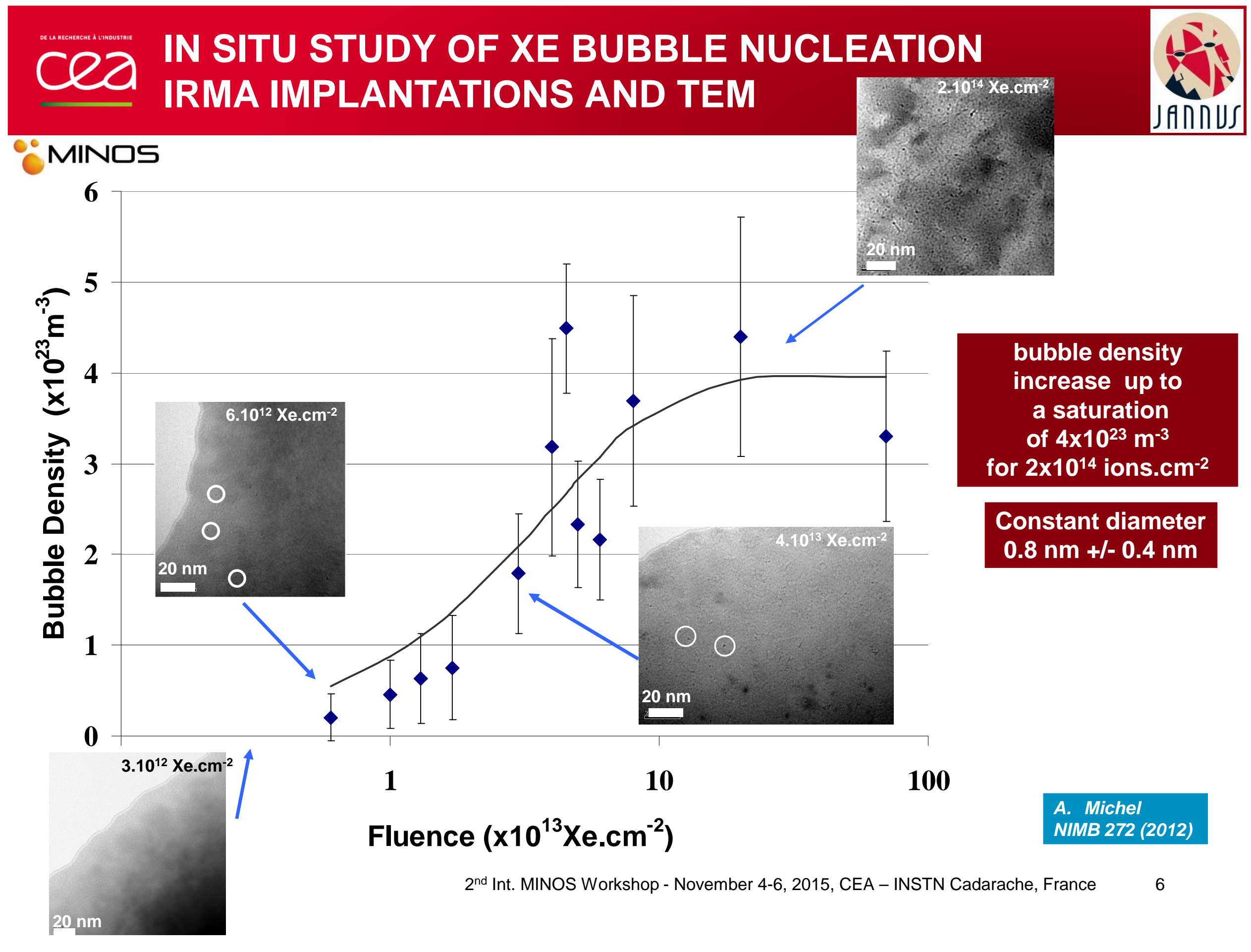




\section{cea}

\section{IN SITU STUDY OF CAVITY NUCLEATION}

ARAMIS IRRADIATION AND TEM

MIN口S

Energy $4 \mathrm{MeV}$

$\rightarrow 98 \%$ of Au ions through the thin foil

$\rightarrow$ creation only of defects

- Ambient temperature, $6000^{\circ} \mathrm{C}$ and $1000^{\circ} \mathrm{C}$

$\square$ Fluence comprised between $1.3 \times 10^{12}$ to $7 \times 10^{14}$ ions. $\mathrm{cm}^{-2}$

$\rightarrow$ Defects : $10^{-2}$ to $1.4 \mathrm{dpa}$
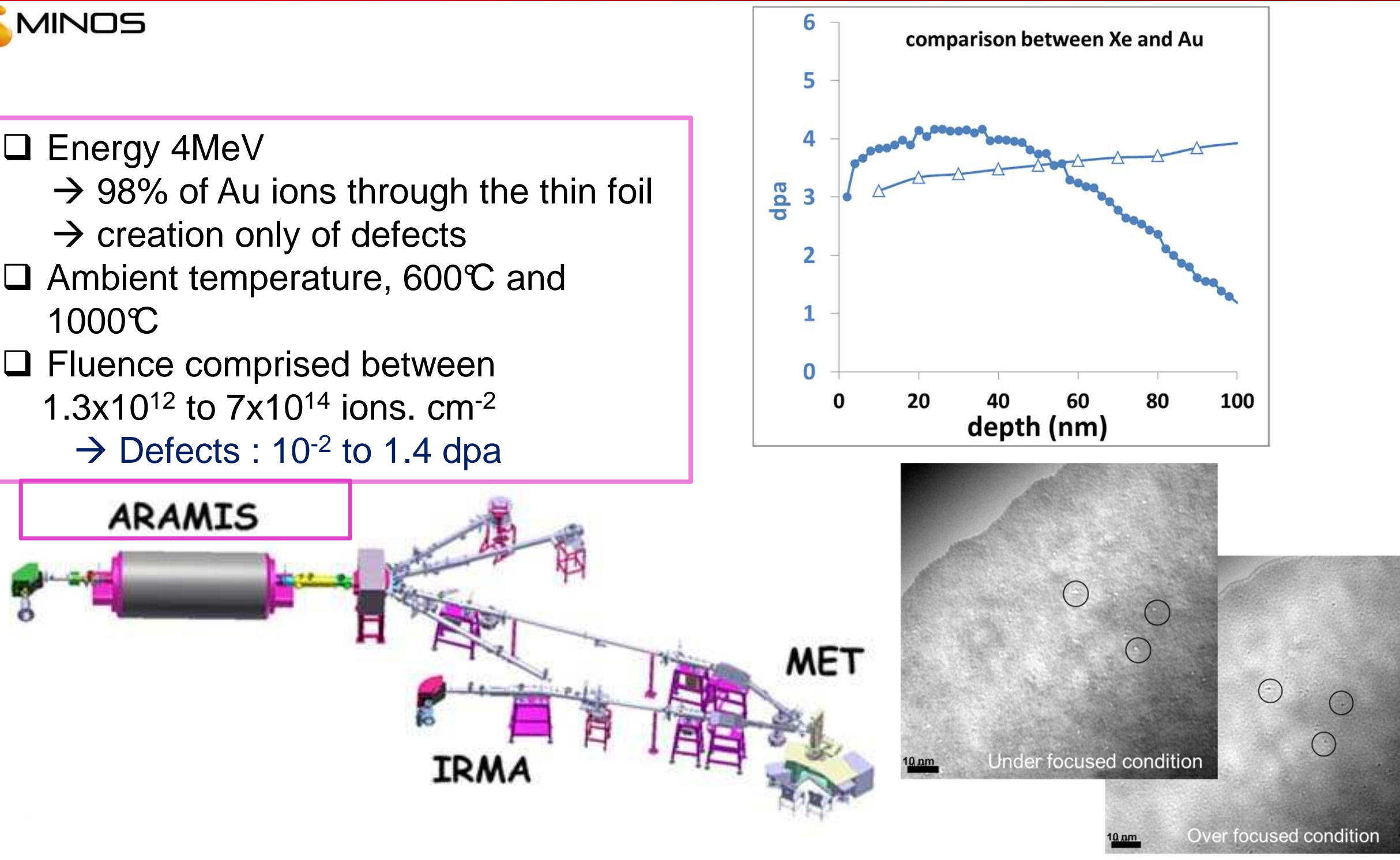


\section{IN SITU STUDY OF CAVITY NUCLEATION} ARAMIS IRRADIATION AND TEM

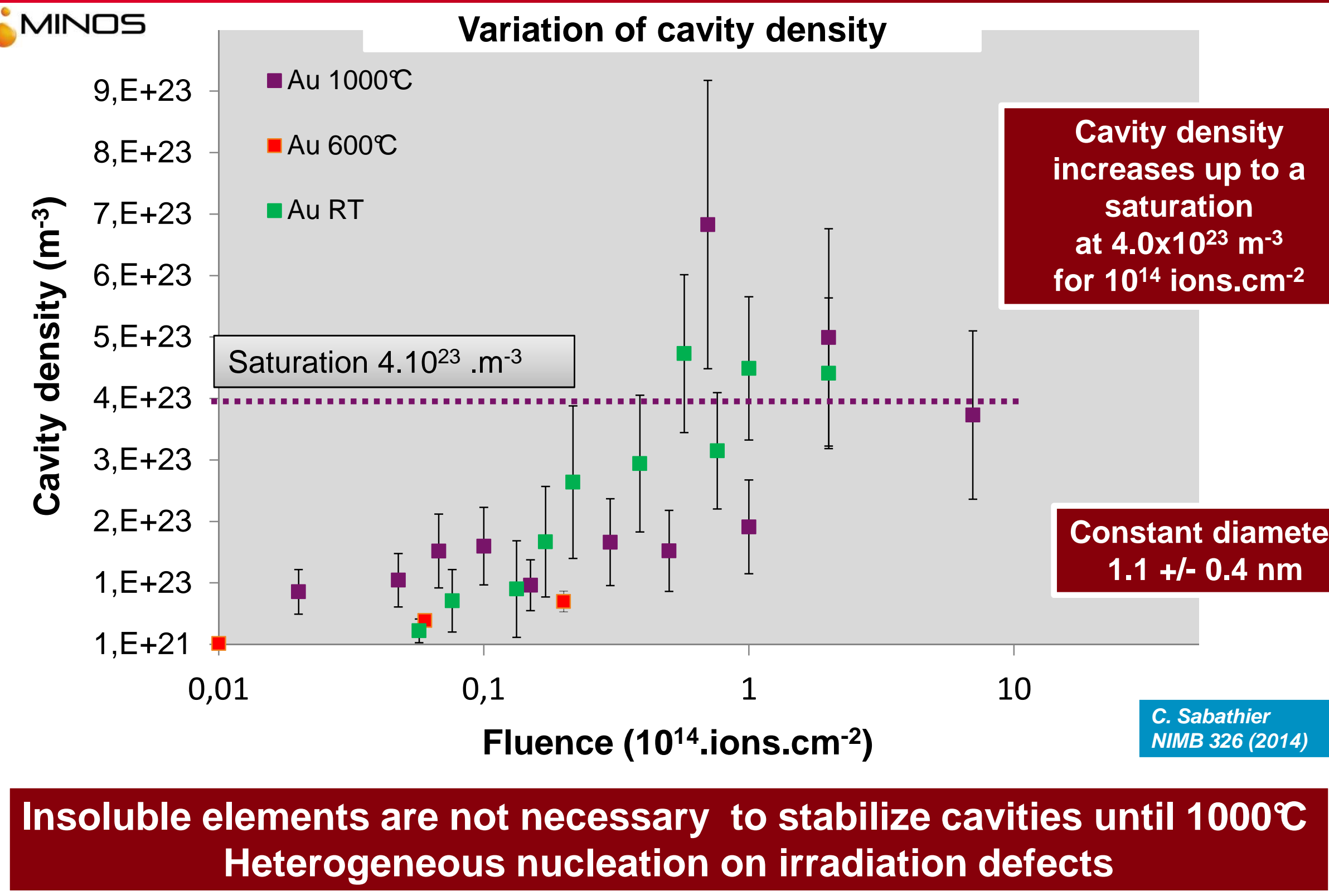




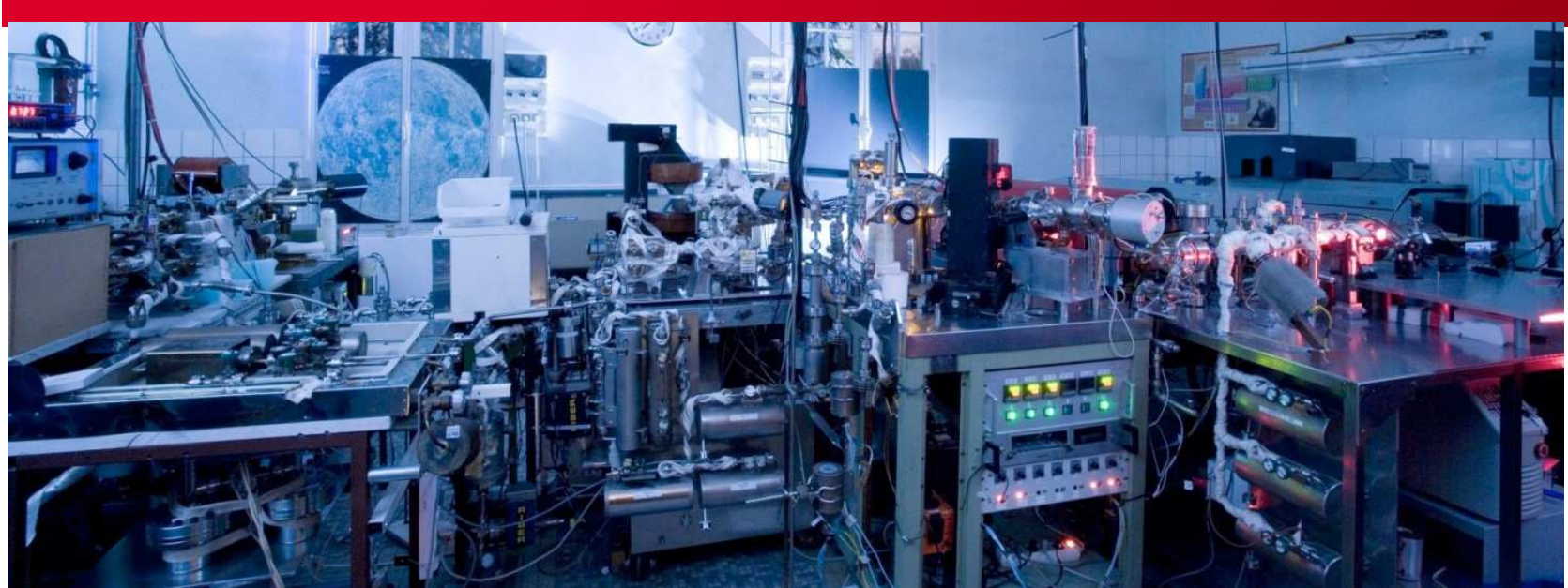

The platform is used to detect and analyse traces of isotopic rare gases with a detection limit of $10^{5} \mathrm{Kr}$ or $\mathrm{Xe}$ atoms

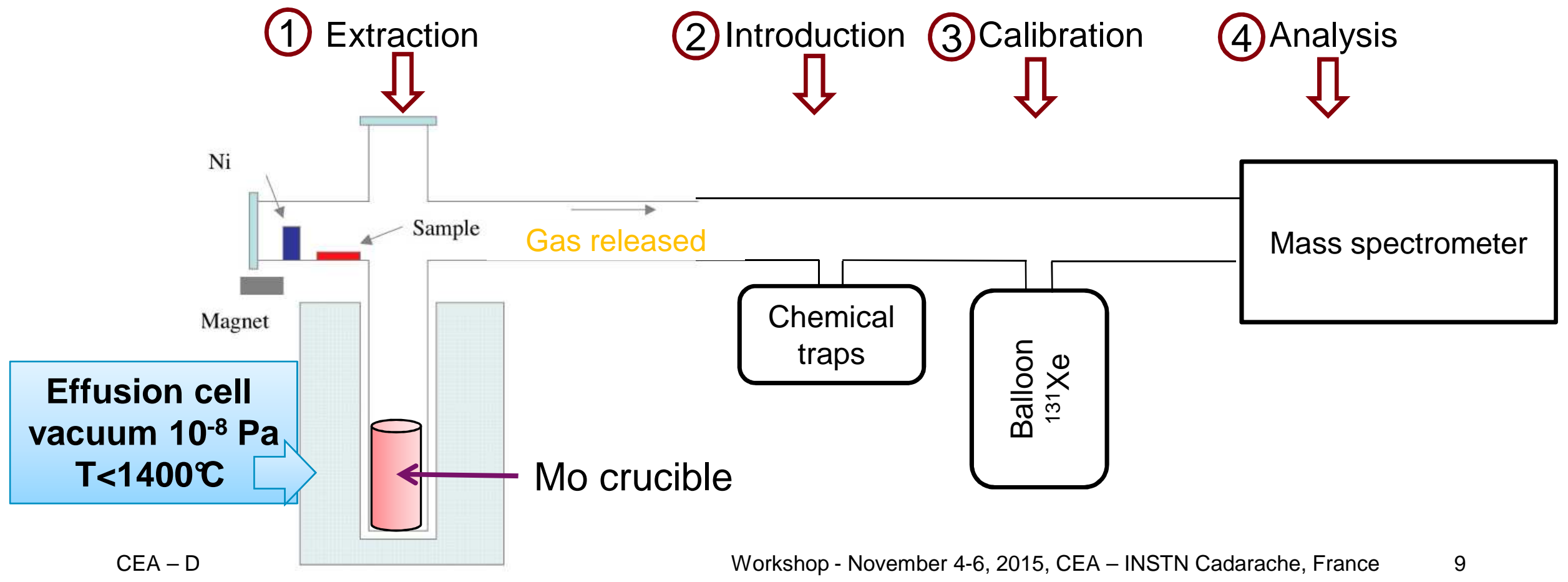




\section{CeZ STUDY OF XENON DIFFUSION IN UO PIAGARA PLATFORM (CNRS/CENBG)}

MINDS

- Implantation Xe at $400 \mathrm{keV}$

Fluence $9 \times 10^{11}$ at.cm $^{-2} \rightarrow 1.4 \mathrm{ppm}-2.10^{-3} \mathrm{dpa}$

- Temperature range : $1150^{\circ} \mathrm{C}-1350^{\circ} \mathrm{C}$
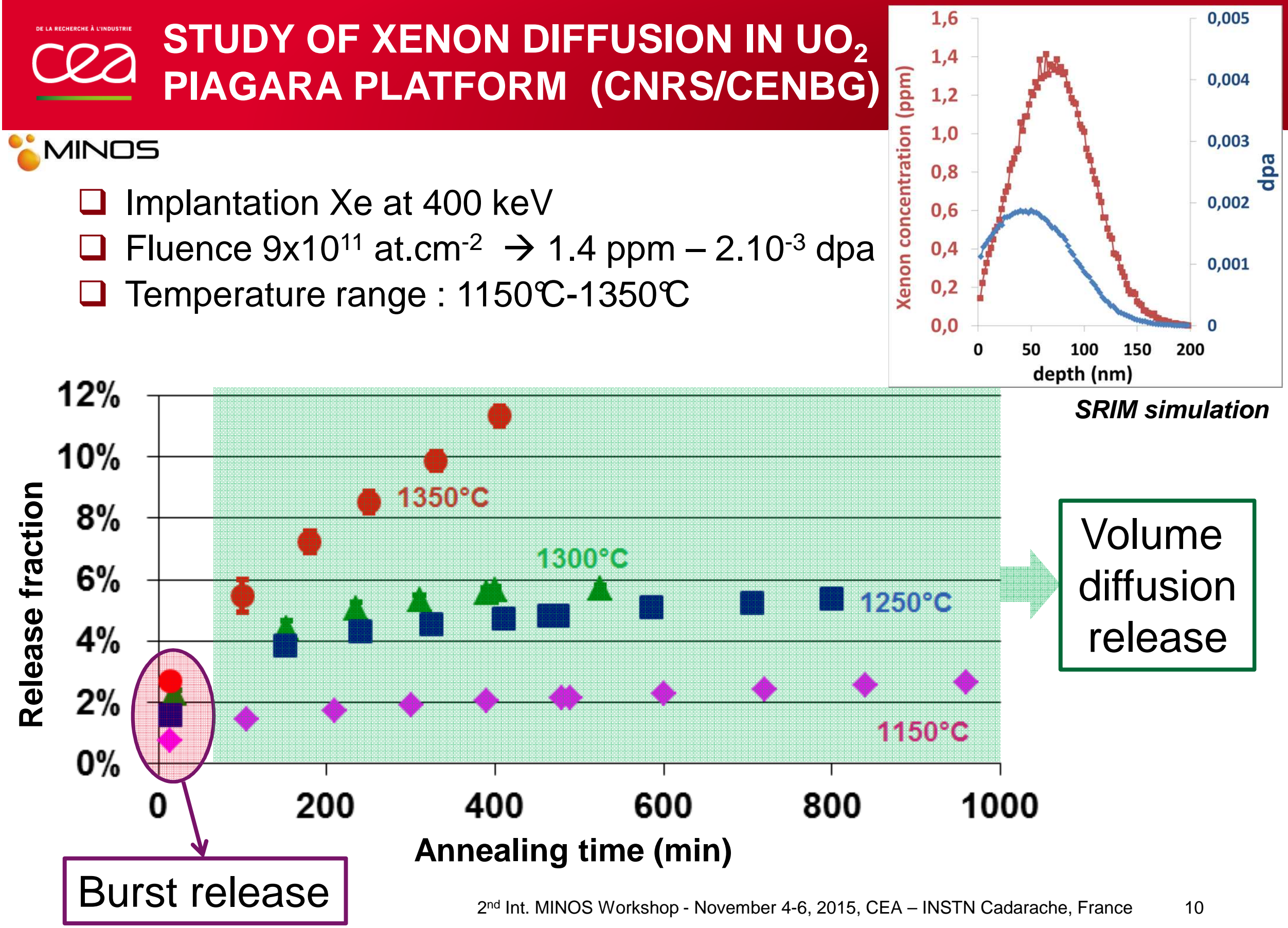


\section{CeZ STUDY OF XENON DIFFUSION IN UO PIAGARA PLATFORM (CNRS/CENBG)}

\section{\&ENBG}

\section{MINDS}

- Second Fick law $\frac{\partial C(x, t)}{\partial t}=\frac{\partial}{\partial x}\left(D(x) \frac{\partial C(x, t)}{\partial x}\right)$

Limit conditions $C(0, t)=0$ and $C(\infty, t)=0$

- Initial profile $\mathrm{C}(\mathrm{x}, 0)$ : SRIM simulation
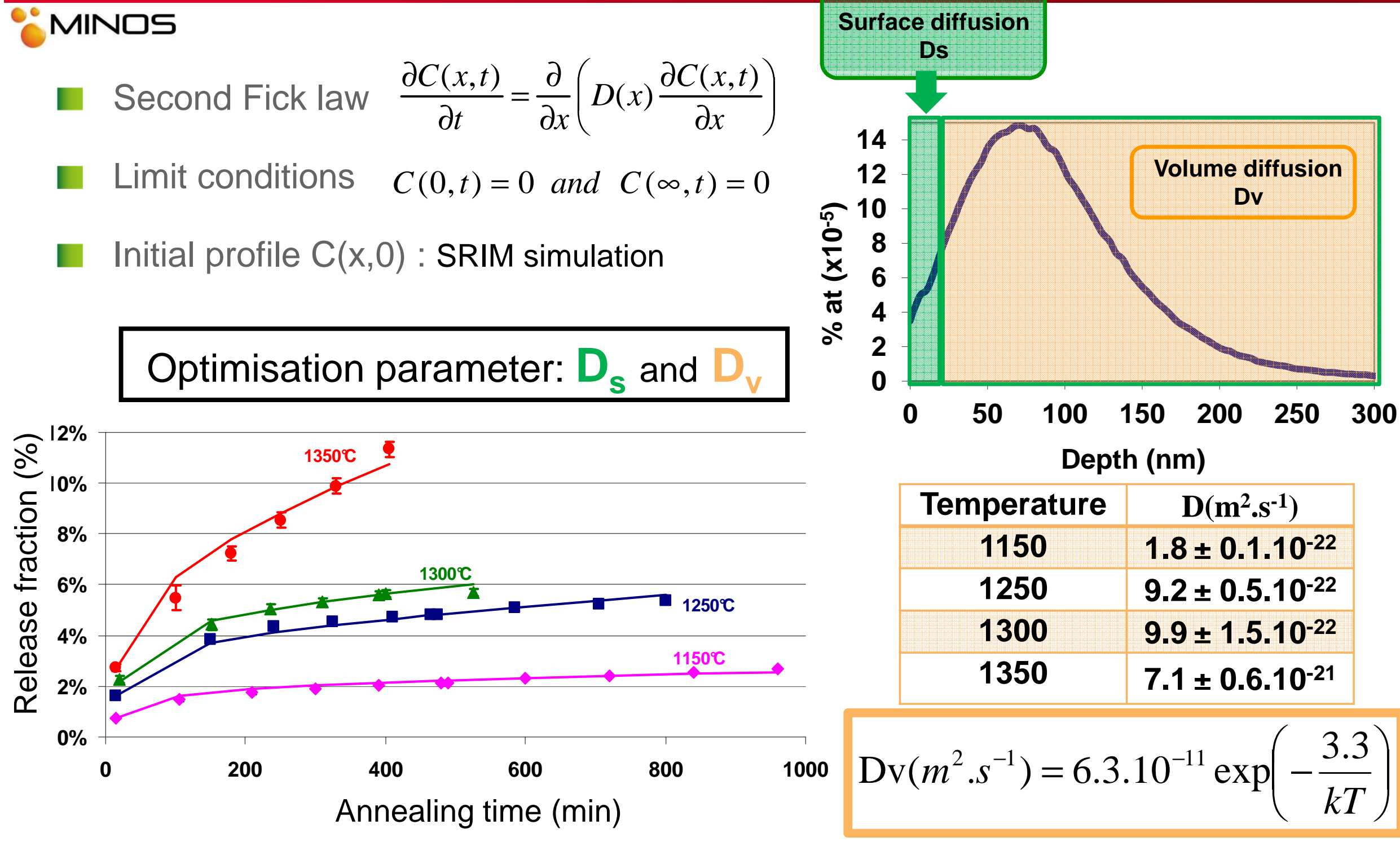


\section{CEA STUDY OF XENON DIFFUSION IN UO PIAGARA PLATFORM (CNRS/CENBG)}

MINDS

$\square$ Important literature on xenon diffusion $\Rightarrow$ dispersion on diffusion coefficient

- Experimental parameters to determine intrinsic diffusion coefficient

$>$ burn-up

$>$ stoichiometry

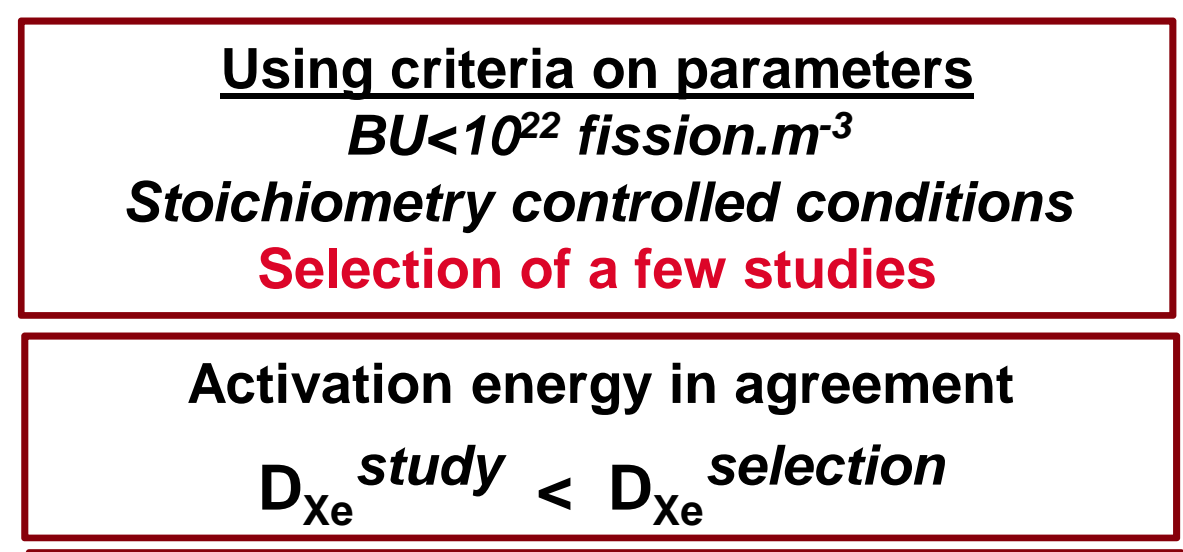

Kaimal's study $10^{24}$ fission.m ${ }^{3}$

In our study: low fluence to see nano cavity by TEM but xenon can be trapped in smaller irradiation defects

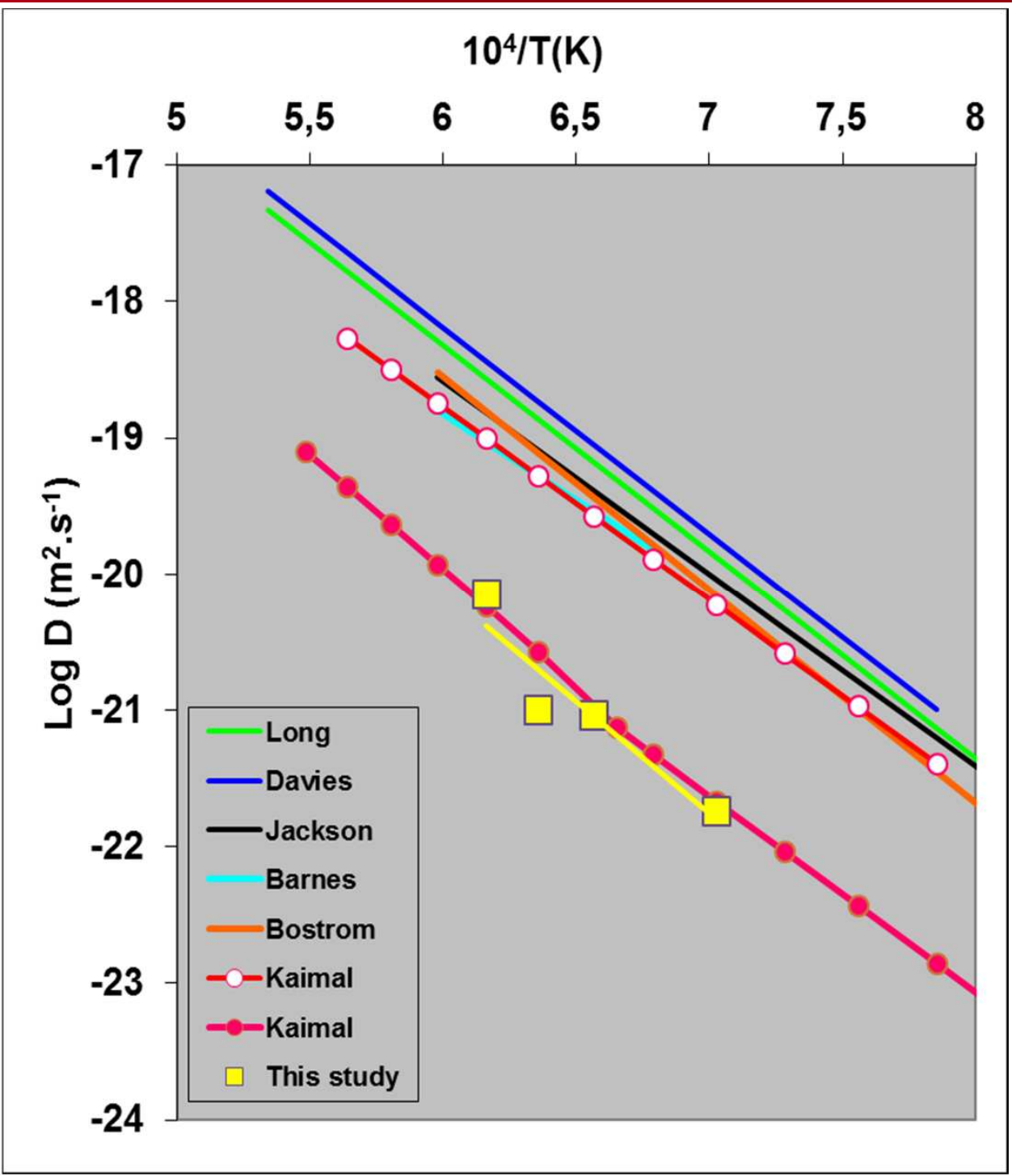




\section{CONCLUSION AND PERSPECTIVE}

MINDS

Study of the nucleation as a function of the ion fluence and temperature

$>$ No change in cavity size: diameter $\sim 1 \mathrm{~nm}$

$>$ Cavity density increases with fluence until a threshold density $\sim 10^{23}$ cavity. $\mathrm{m}^{-3}$

$>$ No dependence of temperature until $1000^{\circ} \mathrm{C}$

No need for insoluble elements to stabilize cavities until $1000^{\circ} \mathrm{C}$ Heterogeneous nucleation on irradiation defects

\section{Study of xenon diffusion}

$>$ Determination of the Arrhenius law governing xenon diffusion

$>$ Although experiments are performed at very low implantation fluences, a trapped xenon effect can appear

$>$ Next experiments: xenon diffusion as a function of the fluence

$>$ Release measurements with PIAGARA Platform

$>$ Cavity characterisation by TEM

$>$ Defect characterisation by Positron Annihilation Spectroscopy (CEMHTI) 